\title{
e-Migrinter
}

$8 \mid 2012$

Regards sur les migrations sud-asiatiques

\section{Migrations et transferts fonciers ruraux : étude villageoise dans la zone péri-urbaine de Bamako}

\section{Larry Becker}

\section{(2) OpenEdition}

\section{Journals}

Édition électronique

URL : https://journals.openedition.org/e-migrinter/605

DOI : $10.4000 /$ e-migrinter.605

ISSN : 1961-9685

Éditeur

UMR 7301 - Migrinter

Édition imprimée

Date de publication : 4 avril 2012

Pagination : 104-108

ISSN : 1961-9685

\section{Référence électronique}

Larry Becker, « Migrations et transferts fonciers ruraux : étude villageoise dans la zone péri-urbaine de Bamako », e-Migrinter [En ligne], 8| 2012, mis en ligne le, consulté le 20 mai 2021. URL : http:// journals.openedition.org/e-migrinter/605; DOI : https://doi.org/10.4000/e-migrinter.605 


\title{
VIE DE LABO
}

\section{Note de Terrain : Migrations et transferts fonciers ruraux : étude villageoise dans la zone péri-urbaine de Bamako}

\author{
Larry Becker
}

\section{$L$}

arry Becker est professeur de géographie à l'Oregon State University à Corvallis aux Etats-Unis. Il a passé dix mois (août 2010 à juillet 2011) au laboratoire MIGRINTER en tant que chercheur invité par Véronique Lassailly-Jacob dans le cadre du Programme régional de bourses de recherche de la région PoitouCharentes. Ce séjour lui a également permis de mener des recherches sur le terrain dans un village de la zone péri-urbaine de Bamako. Initialement venu pour une année sabbatique de recherches sur la migration des riziculteurs en Côte d'Ivoire, il devait changer le thème de son étude après le décès d'un collègue en Côte d'Ivoire et les événements politiques dans le pays.
Les recherches de Larry Becker partent de l'hypothèse que les remises des migrants sont plus efficaces pour le développement que la vente des terres. Elles permettent, entre autre, d'entretenir les liens sociaux au sein des familles et du village. L'étude de cas menée en zone rurale autour de Bamako a permis de se pencher sur les problèmes liés à la vente de terre comme solution aux besoins courant de liquidités.

Les transferts de terres constituent une des problématiques majeures des recherches contemporaines sur l'Afrique rurale. Selon la perspective adoptée, ils sont caractérisés comme des accaparements de terres ou comme des investissements directs étrangers. Indépendamment de ces points de vue, ces transactions foncières à grande échelle dans les pays africains amènent le transfert de milliers d'hectares de terres à des entités étrangères, que ce soit les gouvernements ou des sociétés privées.

Moins médiatisées, et à des échelles plus locales, les relations homme-terre évoluent en lien avec l'application progressive des réformes économiques néolibérales, la décentralisation politique ainsi que le mouvement naturel de l'accroissement démographique. Les agriculteurs possédant des terres par le jeu foncier des lois coutumières les vendent. Lorsque la demande en terres augmente, la pression foncière entraîne la création d'un marché avec des titres fonciers formels. Les politiques visant à encourager les registres fonciers et la privatisation ont reçu le soutien 


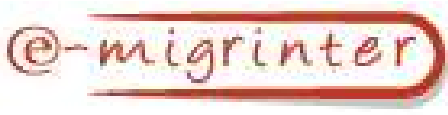

de la Banque mondiale et du Programme des Nations Unies pour le Développement en raison du potentiel que les titres fonciers formels possèdent pour assurer aux agriculteurs une reconnaissance de leurs ressources foncières sur le marché. Cette approche visant à réduire la pauvreté grâce à la restructuration des marchés fonciers s'oppose à celle qui considère les marchés fonciers comme prédateurs pour les paysans pauvres puisqu'entérinant la perte des terres issues des droits coutumiers, donc nonmarchands.
La question du lien entre migrations internes et internationales et ces bouleversements dans le monde paysan est à approfondir. La recherche menée à Bamako et au sein du laboratoire Migrinter a permis d'identifier les changements du système agraire dans un village de la zone périurbaine de Bamako, signalant ainsi que contrairement à la migration, la vente de terres villageoises rompt les relations sociales et économiques à la base de la communauté rurale.

Photo $\mathrm{n}^{\circ} \mathbf{1}$ : Larry Becker avec un membre d'une famille du village de Soro qui a vendu des terres. Cette famille bénéfice également des revenus d'un autre membre qui est revenu d'une migration à Dubaï.

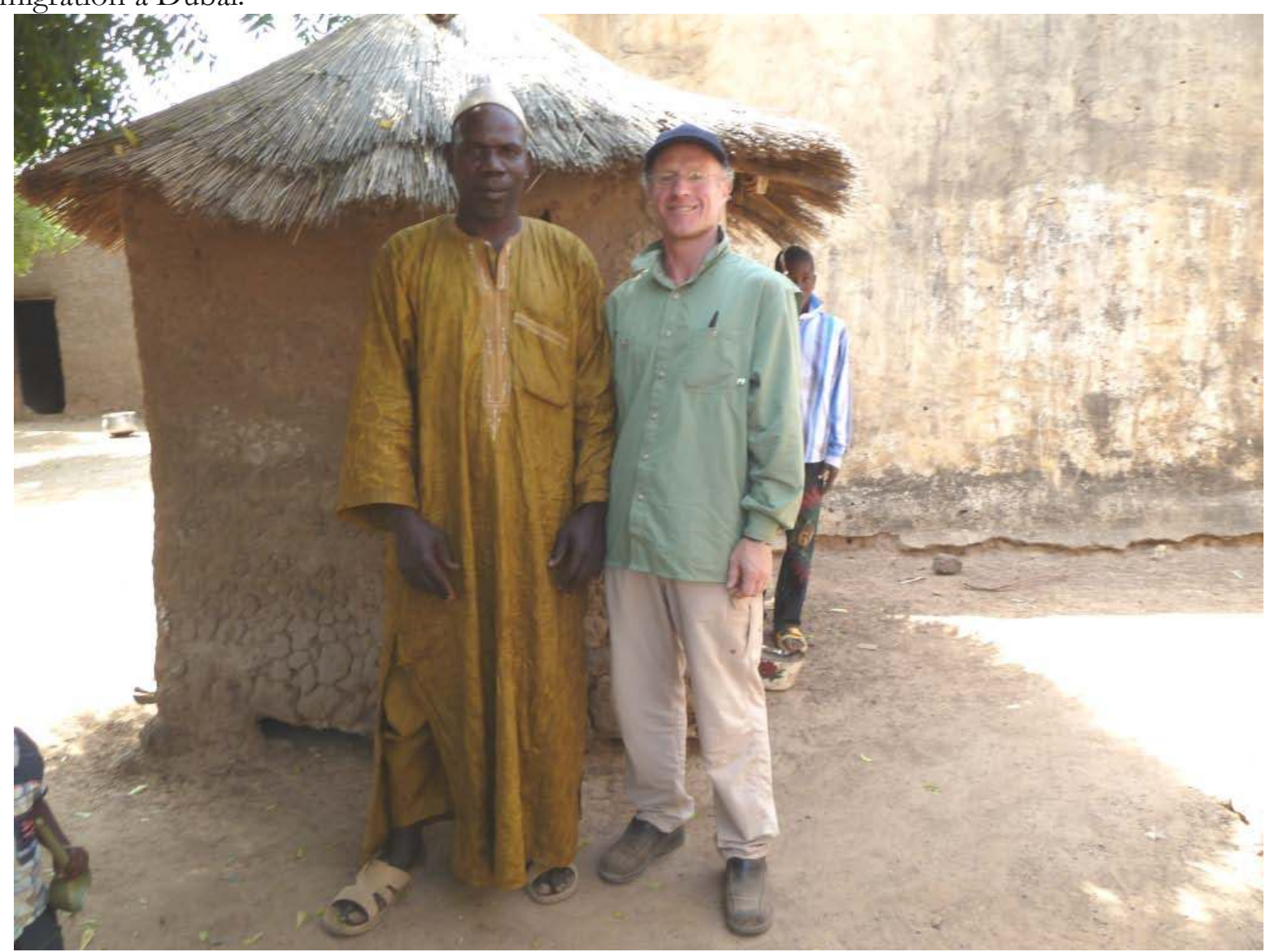

Sources : Larry Becker

À partir d'une recherche de terrain en janvier-février 2011 et en s'appuyant sur les précédents séjours en 1987 et 1996, cette étude examine l'impact du marché foncier naissant sur le village de Soro situé en zone péri-urbaine de Bamako. Résidant dans le village, j'ai recueilli des données à partir d'entretiens avec les représentants des 39 ménages du village. Ces entretiens ont fourni des informations sur les changements 
démographiques, la dynamique des ménages et la production. Ils ont également servi à formuler de nouvelles questions, notamment sur la vente de terres agricoles, questions approfondies à travers des entretiens informels avec des femmes chefs de ménage, les aînés et leurs jeunes frères.

Plus précisément, cette étude examine comment les paysans jusque-là engagés dans une agriculture de subsistance se positionnent pour répondre à un nouveau marché foncier agricole.

En outre, dans quelle mesure la vente de terre représente-t-elle une nouvelle forme d'articulation avec le marché, remplaçant le couple traditionnel migration et culture de rente?

La terre et le travail sont devenus des marchandises en raison de l'ajustement structurel et de la libéralisation du marché. À son tour, la décentralisation tend à augmenter les inégalités sociales: certains groupes sociaux ont en effet un accès privilégié au pouvoir et à certaines ressources, dont la terre. Le système lignager qui utilisait la migration et les cultures commerciales pour s'adapter aux demandes du marché a perdu sa flexibilité face aux demandes de terres émises par les résidents salariés du centre urbain voisin.

Au village de Soro, la première vente de terre a eu lieu autour de 2001-2002. Au début de l'année 2011, un hectare de terre est vendu pour 100000 à 250000 francs CFA (154 à $386 €$ ). La terre la moins chère est située loin des routes principales et est constituée de sols à faible potentiel agricole. Un villageois a estimé que près de 500 hectares de terres avaient été vendus par l'un des chefs de famille du lignage fondateur. Selon un des enseignants à l'école du village, plus de 50 millions de francs CFA de terres avaient été vendues, corroborant ainsi l'estimation de 500 hectares.
Jusqu'à présent, les paysans du village affirment que les terrains vendus aux étrangers ne sont pas cultivables. Ce sont des zones topographiquement plus élevées, comprenant également les basses collines (tintinw). Ces zones sont rocailleuses et comportent d'importantes quantités de graviers (bèlèdugu), leurs sols latéritiques (fuga) n'ont qu'un faible intérêt pour les villageois qui cultivent principalement les sols de la plaine profonde (fala). Les arbres de karité sont les plus abondants dans les sols fala. Les zones fala appartiennent à des lignées Bambara établies de longue date, mais sont aussi exploitées par des familles Peuls et Bozo.

Dans le village, les opinions au sujet de la vente de terrains sont divisées. Un villageois du lignage fondateur qui a vendu des terres nous a fait remarquer que s'il n'avait pas profité de la vente de terrains, il aurait suffi aux acheteurs des villes d'aller dans un village voisin. Son raisonnement, même s'il reconnait la vente de terres comme une perte du patrimoine et des ressources, repose sur le principe selon lequel les acheteurs sont si nombreux que les ventes de terres sont inévitables. Le village, et lui en particulier, pourraient ainsi profiter de ces ventes. Des jeunes du village, également à la recherche d'acheteurs pour leurs terres, sont particulièrement enthousiastes à la perspective de cette future vente, cela leur permettant d'envisager la possibilité d'un avenir sans le travail acharné de la culture du sorgho.

Cependant, tout le monde au village ne peut pas vendre la terre. Les femmes et les nouveaux arrivés n'y sont pas autorisés. L'accès des femmes à la terre se fait à travers le mariage. Les nouveaux arrivés peuvent acquérir des terres grâce à l'approbation du chef de village. Les villageois qui ont exprimé leur désapprobation face à la vente des terres sont ceux qui n'ont pas le droit de vendre. Ils sont issus des lignées nyamakala, dernières arrivées dans le village et non Bambara. Les femmes se positionnent 


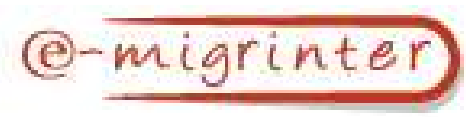

souvent aussi contre la vente de terres. Certains d'entre eux avancent que la vente de terres divise les habitants du village, les rendant inégaux face à l'accès à d'éventuelles ressources financières.

Alors que la vente de terres bouleverse les relations sociales, la migration, au contraire, peut avoir un effet complémentaire du système traditionnel de culture, notamment lorsqu'elle fournit des remises. De plus, la migration apparait la plupart du temps comme saisonnière ou temporaire, alors que la vente de terres est, quant à elle, définitive. Près des trois quarts des ménages de Soro comptent un migrant interne et près d'un tiers, un migrant international. Les envois de fonds contribuent à soutenir les ménages, même si certaines familles ont perdu le contact avec les migrants. Ces données soulignent le rôle ambigu joué par la migration pour le développement du village de Soro.

Photo $\mathbf{n}^{\circ} 2$ : Résidant du village de Soro qui ne peut pas vendre sa terre. Il est en train de montrer un terrain à coté du sien qui a été vendu à un résidant de la ville de Bamako.

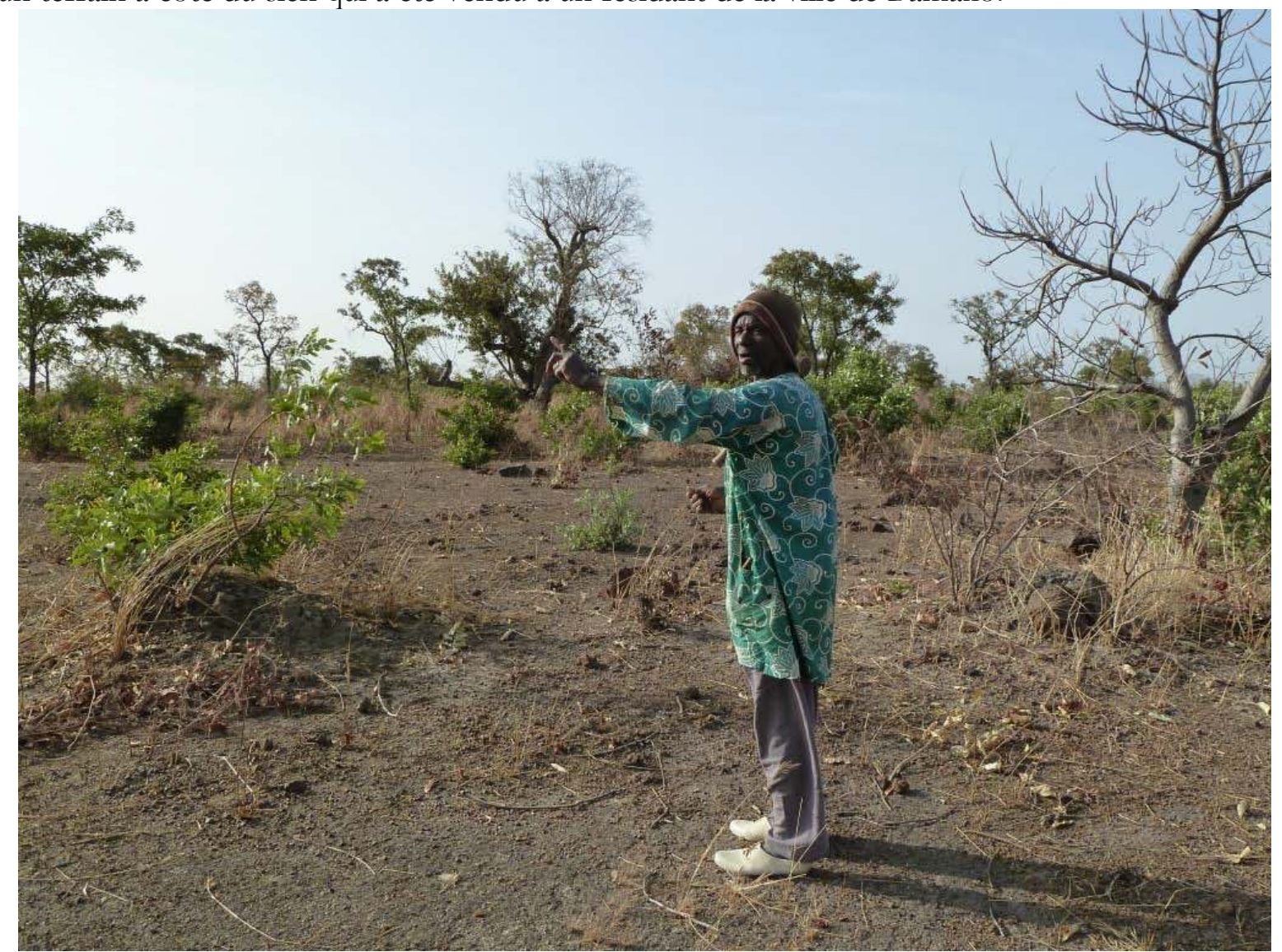

Source : Larry Becker

L'effet des ventes de terrains sur le développement est visible en terme de bénéfices immédiats grâce à l'apport directe de liquidités. Paul Pélissier soutenait, en 1995, que les ventes de terres dans les zones périurbaines en Afrique entravaient l'autosuffisance alimentaire, et Bréhima Béridogo, en 2003, écrivait la même chose pour le Mali. Les ventes de terrains créent un conflit puisque la terre est retirée du contrôle de la lignée. Les relations sociales formées pour assurer une production de subsistance et la reproduction de la prochaine génération sont rompues. Pour la génération actuelle, 
les revenus de certains ménages privilégiés ont augmenté, mais les villageois qui n'ont pas le droit de vendre la terre sont exclus. Quand toutes les terres seront vendues les villageois n'auront que deux options: cultiver des céréales pour tenter de relancer le système agricole ancien, ou quitter le village, faute de ressources suffisantes. À moins que des revenus provenant de la vente des terres soient investis dans la transformation de l'économie (thèse pour laquelle il existe peu de preuves d'aujourd'hui) de telle manière que les clivages sociaux soient minimisés. La logique de marché de plus en plus forte semble destinée à changer radicalement le fonctionnement du village à l'horizon de la prochaine génération.

Un article basé sur cette étude est actuellement en cours d'examen par le Journal Geoforum.

Larry BECKER

Associate Professor Geography College of Earth, Ocean and Atmospheric Sciences (CEOAS)

Oregon State University 104 Wilkinson Hall Corvallis, OR 97331 Etats-Unis beckerla@geo.oregonstate.edu Tél. (+1) 541-737-9504

\section{Bibliographie}

Pélissier, Paul (1995) Campagnes africaines en devenir, Paris, Arguments, 318 p.

Béridogo, Bréhima (2003) Les interactions rurales et urbaines dans le site périurbain de Moribabugu (Mali), Recherches Africaines, $\mathrm{n}^{\circ} 2$, [en ligne]: http://www.recherchesafricaines.net/document.php?id=156.ISSN1 817-423X 